Cite as: Colvin-Sterling, S. (2016). The correlation between temperament, technology preference, and proficiency in middle school students. Journal of Information Technology Education: Research, 15, 1-18. Retrieved from http://www.jite.org/documents/Vol15/JITEv15ResearchP001-018Colvin1768.pdf

\title{
The Correlation between Temperament, Technology Preference, and Proficiency in Middle School Students
}

\author{
Sabrina Colvin-Sterling \\ Camden County Schools, Kingsland, GA, USA
}

\author{
ssterling@camden.k12.ga.us
}

\begin{abstract}
This study examined the relationship between middle school students' personality type and their academic performance in the technology courses in which they participated. It also explored the differences in technology use by personality. Most participants identified games as a favorite pastime. However, there were some noted temperamental differences. Students with the analytical personality reported the most varied use of computers, and rated their technology skills significantly higher on the self-perception scales and performed at a higher proficiency level than their peers. The study also investigated the effectiveness of the two computer courses offered at the schools in the study. Students who completed the Computer Literacy course during the school year performed significantly higher than those who took the Explorations Technology course, both courses, or no technology course at all. However, those with the analytical temperament performed better in the Explorations Technology course. Results suggest personality can predict technology use in students. Findings are consistent with similar research in the computing industry.
\end{abstract}

Keywords: technology, temperament, MBTI, True Colors, KTS, differentiation, personality type

\section{Introduction}

Technology has forever changed the educational landscape, giving teachers new classroom challenges. Educators must develop their personal technological proficiency while supporting students in the acquisition of skills and ethical use of new technology tools. Although students are often ahead of the curve in mastering technology (Purcell, Heaps, Buchanan, \& Friedrich, 2013), they need guidance to develop full competence. Today's teachers also face the task of preparing students for jobs that have yet to be created (Eisner, 2010).

Most twenty-first century employers require employees to enter the workforce with a strong base

Material published as part of this publication, either on-line or in print, is copyrighted by the Informing Science Institute. Permission to make digital or paper copy of part or all of these works for personal or classroom use is granted without fee provided that the copies are not made or distributed for profit or commercial advantage AND that copies 1) bear this notice in full and 2) give the full citation on the first page. It is permissible to abstract these works so long as credit is given. To copy in all other cases or to republish or to post on a server or to redistribute to lists requires specific permission and payment of a fee. Contact Publisher@InformingScience.org to request redistribution permission. of technology skills, and a foundation upon which to grow. Additionally, with computer automation outsourcing jobs overseas, there is a greater need for creative, cooperative, and empathetic application of technology in order for students to remain competitive (Ohler, 1999, 2010; Pink 2009). Pink (2006) suggests that students who possess strength in design, story, symphony, empathy, play, and meaning are less 
likely to pursue tech-related fields. Those students also use fewer applications in the workplace (de Vreede, de Vreede, Ashley, \& Reiter-Palmon, 2012). Yet, the aforementioned qualities are fundamental characteristics for effectiveness in a global work environment. Conversely, technology 'types' tend to be practical and matter-of-fact in an era where creative interpersonal skills are as important as understanding computer systems (Pink, 2006). Therefore, 'techies' may need to develop new capabilities to meet new demands.

Using personality type or temperament tools can provide additional insight. Personality assessment has been used to help employees in many vocations understand their peers and clientele (Khan, Javaid \& Farooq, 2015). Similarly, with the strong correlations to learning styles, personality tools can help teachers make instructional decisions and guide students towards career choices while simultaneously fostering classroom relationships (Conti \& McNeil 2011; Nickels, Parris, Gossett, \& Alexander, 2010).

Learners focus on, process, and master information at varying rates. Students learn well with teachers who understand and accommodate learning styles by adapting instructional methods to meet educational needs (Bolhari \& Dasmah, 2013). Personality scales offer insight on word use, story-telling patterns, and participation level (Thorne, Korobov, \& Morgan, 2007). They also predict the level of a student's linguistic complexity (Sadeghi, Kasim, Tan, \& Abdullah, 2012). Personality is correlated with problem-solving strategies, gifted education placement and academic risk (McPeek, Urquhart, Breiner, Holland, \& Cavalleri 2011). Personality can predict user interaction styles as well as team member selection (D’Souza \& Colarelli, 2010; Luse, McElroy, Townsend, \& DeMarie, 2013). Additionally, students can use type knowledge to better explain their cognitive and emotional needs to others.

\section{Method}

The study addressed the following questions:

1. What is the relationship between personality and technology performance in the state technology tests?

2. What is the relationship between personality and student technology use outside of the classroom? Does it impact performance in the state technology tests?

3. Does student performance in the state tests differ by technology course participation?

\section{Participants and Setting}

The population included 647 eighth grade students from two southeast Georgia middle schools, of which 314 completed the True Colors Splash Test. Ages ranged from 13.5 to 16.5 years, with a mean of 14.5 years. The actual sample consisted of 194 students who met a dominant temperament score of $34 \%$ or higher, with 105 males $(54 \%)$ and 89 females (46\%). This included a few more males than was representative of the eighth grade population, consisting of $50.9 \%$ males to $49.1 \%$ females. The majority of students participated in at least one technology course.

\section{Research Model}

The study employed a control group/study group design using post-test only analysis, and incorporated multivariate correlation, Analysis of Variance (ANOVA), and multivariate regression analysis. The methods were selected to investigate the relationship between temperament and technology proficiency, and account for the possible differences between students' performance in the technology programs. Correlational research helps organizations make reasonable predictions and guide future endeavors. If temperament can help predict interest and aptitude, educators can make more informed curriculum decisions that effectively meet student needs in the technol- 
ogy classroom. The posttest only experimental design was used to address any potential threats to internal and external validity (Campbell \& Stanley, 1963).

\section{Instrumentation}

The dependent variable, technological proficiency, was measured using two state tests; the Georgia $8^{\text {th }}$ Grade Technology Literacy test ( $8^{\text {th }}$ Grade Tech-Literacy), a 78 question multiple-choice assessment aligned to both state and national standards, and the 21 st Century Skills test $\left(21^{\text {st }}\right.$ Century) from Learning.com. Technology use was measured using the survey included with the Learning.com test along with a few user created open-ended items.

The predictor variable, personality type or temperament, was measured using the True Colors Splash Test (TCST). This short personality assessment created by Don Lowry is based on the Keirsey Temperament Sorter (KTS) and has been correlated to both the KTS and the MyersBriggs Type Indicator (MBTI) (Wichard, 2006). The TCST incorporates a set of images along with five sets of word clusters. Students evaluate the clusters on a Likert scale, from most like me (4) to least like me (1). This yields an ordinal score (six - 24), categorical measure (color) of Orange/Gold/Blue/Green, and degree of temperamental element displayed as a numeric value.

The temperament descriptions are as follows:

- Orange: Spontaneous, perceptive, hands on, practical, present-oriented, competitive, kinesthetic, concrete-random learners

- Gold: Sensible, judicious, traditional, organized, thorough, achievement-oriented, authoritative, concrete-sequential learners

- Blue: Empathetic, feeling, cooperative, people-oriented, idealists, values harmony, cooperative learners

- Green: Innovative, curious, complex, conceptual, intellectual, independent abstractsequential learners

True Colors was used with students participating in the Career Explorations course and after school clubs as a team building and self-awareness tool.

The school system offered two technology courses: Computer Literacy and Explorations Technology. Computer Literacy focused on the ISTE (2007) national educational technology standards (NETS) while Explorations Technology incorporated several vocational activities in addition to computer literacy. Each course was offered as a quarterly exploratory in 50-minute daily blocks for a total of 34.5 hours.

\section{Data Analysis and Findings}

The data were collected in May 2013. The query included the technology course schedule, technology test scores, survey results, and the True Colors raw scores. Student demographics included gender, gifted education status, socioeconomic status, special education status, ethnicity, and military family affiliation.

Table 1 shows the overall personality distribution of the study population compared to the general population. It also displays the comparative Myers-Briggs and Keirsey personality system terms that correlate to the True Colors terminology. 
Table 1: Proportion of Color Temperaments with Dominant Color above 34\%

\begin{tabular}{|c|c|c|c|c|c|}
\hline Don Lowry - True Colors & Blue & $\underline{\text { Gold }}$ & Green & $\underline{\text { Orange }}$ & Total \\
\hline Myers-Briggs & NF & SJ & NT & SP & \\
\hline Keirsey & Idealist & Guardian & Rational & Artisan & \\
\hline Number in Population & 35 & 25 & 40 & 94 & 194 \\
\hline Study Population Percentage & $18.04 \%$ & $12.89 \%$ & $20.62 \%$ & $48.45 \%$ & $100 \%$ \\
\hline $\begin{array}{l}\text { General Human Population (CAPT, } \\
\text { 2013) }\end{array}$ & $12 \%$ & $38 \%$ & $12 \%$ & $38 \%$ & \\
\hline
\end{tabular}

Figure 1 shows the personality distribution of the study population while Figure 2 show the distribution of the general population.

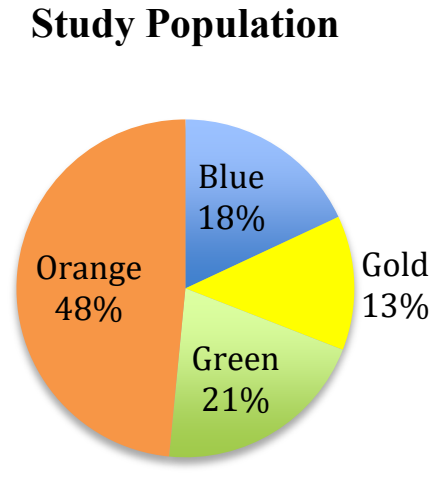

Figure 1. Study population personality distribution

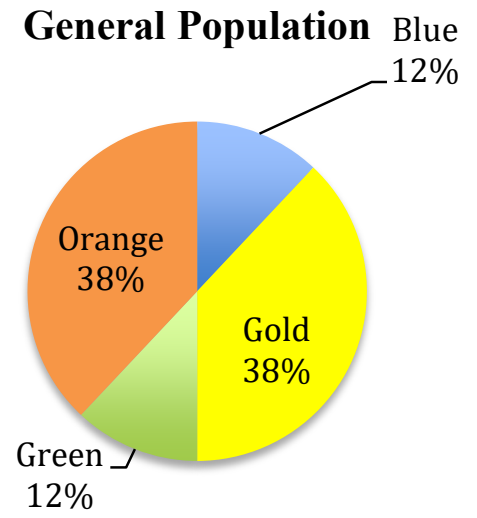

Figure 2. General population personality distribution

A Shapiro-Wilks test ( $\mathrm{p}>.05)$ was conducted to determine the use of parametric vs nonparametric measures. The results are shown in Table 2 and Table 3. A visual inspection of the histograms and normal Q-Q plots showed that the exam scores for both tests were normally distributed for the Blue and Gold groups but not for the Green and Orange groups; therefore, a Kruskal-Wallis test (a non-parametric ANOVA), a Mann-Whitney t-test, and the Spearman's rho tests were used where applicable. 
Table 2. 21st century skills test scaled score $(\mathrm{N}=161)$ Shapiro-Wilk Test

\begin{tabular}{llll}
\hline & $\underline{\text { Statistic }}$ & $\underline{\mathrm{df}}$ & $\underline{\text { Sig. }}$ \\
Blue & .932 & 27 & .077 \\
Gold & .922 & 21 & .095 \\
Green & .920 & 35 & $.014^{*}$ \\
Orange & .965 & 78 & $.032^{*}$ \\
\hline
\end{tabular}

$* \mathrm{p}<0.05, * * \mathrm{p}<.01, * * * \mathrm{p}<.001$

Table 3. ${ }^{\text {th }}$ Grade tech-literacy test score $(\mathrm{N}=182)$ Shapiro-Wilk Test

\begin{tabular}{cccl}
\hline & $\underline{\text { Statistic }}$ & $\underline{\mathrm{df}}$ & $\underline{\text { Sig. }}$ \\
Blue & .968 & 33 & .417 \\
Gold & .919 & 23 & .063 \\
Green & .871 & 38 & $.000^{*}$ \\
Orange & .910 & 88 & $.000^{*}$ \\
\hline$* \mathrm{p}<0.05, * * \mathrm{p}<.01, * * * \mathrm{p}<.001$ & &
\end{tabular}

Figure 3 and Figure 4 show the skewness and kurtosis of the Orange and Green $8^{\text {th }}$ Grade TechLiteracy test results.

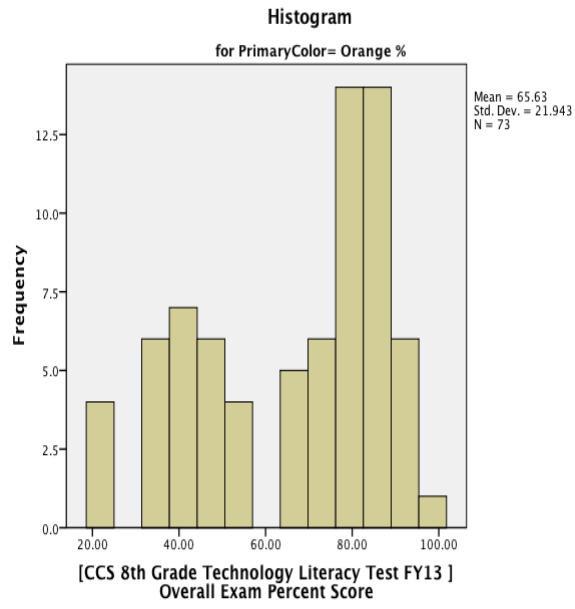

Figure 3. Test score distribution for orange temperament on $8^{\text {th }}$ grade tech- literacy test

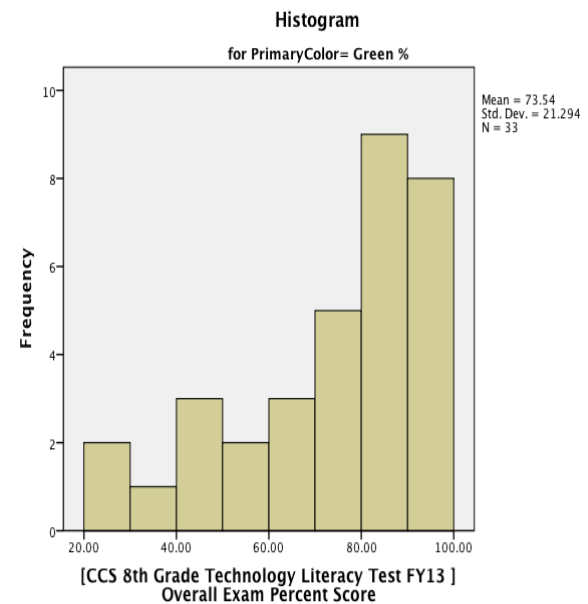

Figure 4. Test score distribution for green temperament for the $8^{\text {th }}$ grade tech-literacy test 


\section{Results by personality and overall test performance}

The $21^{\text {st }}$ Century test reported scaled scores from 200-500. The $8^{\text {th }}$ Grade Tech-Literacy test was reported by percentage. Calculations included the descriptive statistics of frequency, mode, means and standard deviations for the following six domains: technology operations and concepts; research and information fluency; critical thinking; problem solving and decision-making; creativity and innovation; communication and collaboration; and research and information fluency. A Spearman's rho test was conducted to determine if there was a correlation between the spectrum raw scores and the technology exam scores. Results are displayed in Table 4.

Table 4. Spearman's rho test correlations between spectrum measures and tests

\begin{tabular}{llllll}
\hline & $N$ & Blue & Gold & Green & Orange \\
\hline $21^{\text {st }}$ Century & 161 & .024 & $.215^{* *}$ & $.313^{* * *}$ & .086 \\
$8^{\text {th }}$ Grade Tech-Literacy & 182 & -.029 & .106 & $.354^{* * *}$ & .079 \\
\hline
\end{tabular}

${ }^{*} p<0.05, * * p<.01, p<.001 * * *$

The Green (analytical) personality measure and the $21^{\text {st }}$ Century scores were significantly correlated, $r=.313, n=161, p=.000$. There was also a correlation between the Green measure and the $8^{\text {th }}$ Grade Tech-Literacy test, $r=.354, n=183, p=.000$. A weak positive correlation existed between the Gold (organized) measure and the 21 st Century test, $r=.215, n=161, p=.006$. The results suggest that students with the Green temperament were more likely to be proficient on the technology tests.

A Kruskal-Wallis test was conducted to compare the effect of the students' primary temperament on their technology scores. There was a significant difference between the mean scores on the test and having an analytical personality as seen in Table 5 . The performance of students with the Green (analytical) personality was significantly higher on both computer literacy tests.

Table 5. Green temperament difference between means for both tests

\begin{tabular}{lll}
\hline & $\mathrm{N}$ & Kruskal-Wallis test p-value \\
\hline $21^{\text {st }}$ Century & 161 & $.037^{*}$ \\
$8^{\text {th }}$ Grade Tech-Literacy & 182 & $.032^{*}$ \\
\hline${ }^{*}<<0.05, * * p<.01, p<.001 * * *$ & &
\end{tabular}

\section{Results by personality and performance in the technology standards}

The data were analyzed to determine if there were any significant correlations between student temperament and the six technology domains. A Spearman's rho was conducted to determine if there was a correlation between the personality raw score and the technology domains. Results indicated weak to moderate positive correlations for the Green measurement on both tests as seen in Table 6 and Table 7. In Table 6, data also revealed weak positive correlations between the gold measurement and success on the 21 st Century test. Thus, the Gold measure was a secondary indicator of success on that test. 
Table 6. Correlation 21st century skills test scaled score $(\mathrm{N}=161)$

\begin{tabular}{lcccc}
\hline & Blue & Gold & Green & Orange \\
\hline Creativity and innovation & .042 & $.184^{*}$ & $.256^{* *}$ & .060 \\
Communication and collaboration & .029 & $.209^{* *}$ & $.294^{* *}$ & .124 \\
Research and Information fluency & -.021 & $.175^{*}$ & $.344^{* *}$ & .036 \\
Critical thinking, problem solving and decision making & -.019 & $.211^{* *}$ & $.225^{* *}$ & .097 \\
Digital citizenship & .071 & $.208^{* *}$ & $.250^{* *}$ & .053 \\
Technology operations and concepts & .042 & $.166^{*}$ & $.244^{* *}$ & .104 \\
\hline
\end{tabular}

On the 8th Grade Tech-Literacy test, there was a positive correlation between the Green measure (analytical) and each of the test domains. There was also a weak positive correlation between the Orange (spontaneous) measure and critical thinking, problem solving, and decision making $r=$ $.162, n=161, p=.029$. The results, as displayed in Table 7, revealed several weak but nonsignificant negative correlations between the Blue measure and success on the technology standards.

Table 7. Correlation 8th grade tech-literacy $(\mathrm{N}=182)$

\begin{tabular}{lcccc}
\hline & Blue & Gold & Green & Orange \\
\hline Creativity and innovation & .019 & .089 & $.284^{* *}$ & .023 \\
Communication and collaboration & -.064 & .129 & $.277^{* *}$ & .056 \\
Research and Information fluency & -.061 & .034 & $.296^{* *}$ & .044 \\
Critical thinking, problem solving and decision making & -.005 & .129 & $.340^{* *}$ & $.162^{*}$ \\
Digital citizenship & .020 & .097 & $.321^{* *}$ & .078 \\
Technology operations and concepts & -.029 & .108 & $.360^{* *}$ & .076 \\
\hline
\end{tabular}

A Kruskal Wallis test was conducted to determine any statistically significant differences in performance by temperament. The results in Table 8 show the overall proficiency results of the Green students disaggregated by technology standards. On the $21^{\text {st }}$ Century test the Green group attained statistically significant higher scores on Research and information fluency. On the 8th Grade Tech-Literacy test, the students with the Green temperament scored significantly higher on Communications and collaboration was well as Technology operations.

Table 8. Significant Kruskal-Wallis results for green student performance

\begin{tabular}{lll}
\hline & $21^{\text {st }}$ CST $(\mathrm{N}=161)$ & $8^{\text {th }}$ TLT $(\mathrm{N}=183)$ \\
\hline Communication and collaboration & .124 & $.019^{*}$ \\
Research and information fluency & $.014^{*}$ & .087 \\
Technology operations & .109 & $.010^{*}$ \\
$* * \mathrm{p}<.01, * \mathrm{p}<0.05$ & &
\end{tabular}




\section{Results by personal technology use and overall test performance}

To examine the impact of personal technology use on overall test performance, students completed two surveys that consisted of Likert and open-ended questions, rating their computer use and skills on a one to five scale, with five being the highest. An independent t-test was used to determine if there was a significant difference between the survey scores by temperament. Participants with the Green temperament reported the greatest computer use. The results are displayed in Table 9 .

Table 9. Independent t-test personal computer use for green students

\begin{tabular}{lllllll}
\hline Sample & $M$ & difference & $d f$ & $S D$ & t-test result & T-Critical Value \\
\hline Green & $\mathbf{4 . 6 5}$ & 0.50 & 39 & .633 & $\mathbf{3 . 5 7}$ & 1.684 \\
Total & 4.15 & & & & & \\
\hline
\end{tabular}

t-result is significant at $95 \%$ confidence interval

A Spearman's rho test was conducted to determine if there were any correlations between the students' temperament scores and self-perceptions. The statistically significant student selfperceptions are displayed in Table 10.

Table 10: Spearman's rho test p values for student survey and test performance

\begin{tabular}{lll}
\hline & $\begin{array}{l}\text { 8th Grade Tech- } \\
\text { Literacy }\end{array}$ & 21st Century \\
& -.102 & $-.225^{* *}$ \\
Active, Fun-Loving Seeks Variety (Orange) & $-.210^{* *}$ & -.103 \\
Loving, Understanding, Dramatic (Blue) & $.311^{* *}$ & .152 \\
Knows facts, Questioning, Determined (Green) & $-.262^{* *}$ & $-.272^{* *}$ \\
Tender-hearted, Affectionate, Kind (Blue) & $.227^{* *}$ & .120 \\
Complex, Idea person, Competent (Green) & $.214^{* *}$ & $.191^{*}$ \\
Seeks wisdom, Independent, Rational (Green) & $.300^{* *}$ & $.192^{*}$ \\
\hline
\end{tabular}

A qualitative text analysis was conducted to identify frequently used terms and to evaluate the text complexity of the open-ended questions. Table 11 shows the per student ratio scores for the parts of speech along with the complexity and readability factors.

Students with the Orange temperament wrote using simple, easy to understand language while students with the Green temperament wrote more complex, lexically dense sentences. 
Table 11. Text analysis of open-ended responses $(\mathrm{N}=194)$

\begin{tabular}{lllll}
\hline & $\begin{array}{c}\text { Blue } \\
\mathrm{n}=35\end{array}$ & $\begin{array}{l}\text { Gold } \\
\mathrm{n}=25\end{array}$ & $\begin{array}{l}\text { Green } \\
\mathrm{n}=40\end{array}$ & $\begin{array}{l}\text { Orange } \\
\mathrm{n}=94\end{array}$ \\
\hline Adverbs & 0.37 & 0.52 & 0.30 & 0.18 \\
Adjectives & 0.57 & 0.68 & 0.68 & 0.36 \\
Conjunctions & 1.00 & 1.92 & 1.08 & 0.97 \\
Pronouns & 1.63 & 1.80 & 1.58 & 0.99 \\
Prepositions & 1.51 & 1.84 & 1.18 & 1.06 \\
Verbs & 2.29 & 2.76 & 2.58 & 1.97 \\
Nouns & 3.20 & 3.88 & 2.68 & 2.93 \\
Words & 11.37 & 14.40 & 10.60 & 9.17 \\
Characters & 62.46 & 80.56 & 61.00 & 51.83 \\
Complexity factor (Lexical Density) & 73.30 & 69.30 & 62.80 & 41.70 \\
Readability (Gunning-Fog Index): (6-easy 20-hard) & 8.60 & 8.90 & 9.80 & 6.90 \\
Readability (Alternative) beta: (100-easy 20-hard, & 49.10 & 45.60 & 38.50 & 50.90 \\
optimal 60-70) & & & & \\
\hline
\end{tabular}

\section{Results by technology course participation}

To determine the impact of technology course participation on test success, the data were analyzed based on whether students took one course; that is, Computer Literacy or Explorations Technology, both technology courses, or no courses. On the $21^{\text {st }}$ Century test, study participants who took both Computer Literacy and Explorations Technology had an overall mean score of 312.70 compared to a score of 270 for participants who took no computer courses. Students who participated in only the Explorations Technology course had a mean of 300.38 compared to a score of 336.61 for those who only took Computer Literacy as seen in Table 12.

Table 12. 21st century exam scaled score means by course participation $(\mathrm{N}=161)$

\begin{tabular}{lllll}
\hline & Both & None & ET only & CL only \\
\hline Exam Scaled Score & 312.70 & 270.89 & 300.38 & 336.61 \\
\hline
\end{tabular}

On the $8^{\text {th }}$ Grade Tech-Literacy test, study participants who took both Computer Literacy and Explorations Technology had an overall mean percentage of 64.96 compared to a score of 59.88 for participants who took no computer courses. Students who participated in only the Explorations Technology course had a mean of 62.36 compared to a score of 71.02 for those who only took Computer Literacy as displayed in Table 13. 
Table 13. 8th grade tech-literacy test percentage means by course participation $(\mathrm{N}=182)$

\begin{tabular}{lllll}
\hline & $\begin{array}{l}\text { Both } \\
n 269\end{array}$ & $\begin{array}{l}\text { None } \\
n 80\end{array}$ & $\begin{array}{l}\text { ET only } \\
n 92\end{array}$ & $\begin{array}{l}\text { CL only } \\
n 73\end{array}$ \\
\hline Exam Percentage & 64.96 & 59.88 & 62.36 & 71.02 \\
\hline
\end{tabular}

A Mann Whitney t-test was conducted to compare technology test performance by course participation. The data in Table 14 revealed a statistically significant difference between participants in the Computer Literacy course over the other course models. The results suggest that the Computer Literacy course had the greater effect on test performance.

Table 14. Mann-Whitney t-test results for the computer literacy course

$21^{\text {st }}$ Century

Creativity and innovation .020

Communication and collaboration .031

Research and information fluency .033

Technology operations .042

Overall

.026

$8^{\text {th }}$ Grade Tech-Literacy Test

Communication and collaboration

.036

Critical thinking, problem solving, \& decision making

.034

Digital citizenship

.015

Overall

.028

Results significant at $95 \%$ confidence interval

The data indicated no statistically significant positive relationship between the Explorations Technology course and proficiency on the state technology tests. However, the analytical Green students with the highest scores participated in only the Explorations Technology course.

\section{Discussion}

The study analyzed the relationships between middle school students' temperament and their interests, and proficiency levels in technology-related activities in order to achieve its overall purpose - to find ways to differentiate instruction through how students use technology (Uffen, Kaemmerer, \& Breitner, 2013). This section addresses the findings in the light of the research questions formulated earlier.

\section{Personality and Its Impact on Technology Proficiency}

The Green analytical measure on the True Colors spectrum positively correlated with overall technology proficiency as well as success on each of the six standards. With Green dominating the proficiency scores in all areas (Table 4, Table 6, and Table 7), it was important to investigate the ways in which the students used computers in their personal time in order to identify activities 
that would also be appropriate for the classroom. The qualitative word analysis of the open-ended survey responses offered insight on the similarities and differences between the temperament groups. Games placed highest on the list of favorite activities. Students with the Gold or organized preference ranked work second to gaming. Students with the Blue or communicative temperament expressed greater interest in social networking and mentioned several school related tasks. Students with the Orange or spontaneous temperament reported a variety of games, social networking, and multimedia applications. Students with the Green temperament listed more unique devices, multi-user role-playing games, and engaged in more complex computer activities such as programming, coding, and networking. Each temperament possessed at least one of the Computational Thinking dispositions as defined by the International Society for Technology in Education and the Computer Science Teachers Association (Barr, Harrison \& Conery, 2011; Capretz \& Ahmed, 2010; International Society for Technology in Education (ISTE) \& Computer Science Teachers Association (CSTA) [ISTE \& CSTA], 2011 which include but are not limited to:

- Formulating problems in a way that enables us to use a computer and other tools to help solve them

- Logically organizing and analyzing data

- Representing data through abstractions such as models and simulations

- Automating solutions through algorithmic thinking (a series of ordered steps)

- Identifying, analyzing, and implementing possible solutions with the goal of achieving the most efficient and effective combination of steps and resources

- Generalizing and transferring this problem solving process to a wide variety of problems

- Confidence in dealing with complexity

- Persistence in working with difficult problems

- Tolerance for ambiguity

- Ability to deal with open-ended problems

- Ability to communicate and work with others to achieve a common goal or solution

\section{Personality and Personal Technology Use: The Technology Types}

\section{Caring Blue - The communicators}

Students who appreciate cooperative and social activities in the real world take those preferences with them online using computers as productivity and networking tools. This group consistently mentioned friends as a principal component of their technological experience. There was a weak indirect correlation between the scores on the two empathy clusters: 'Tender-hearted, Affectionate, Kind' and 'Loving, Understanding, Dramatic' and scores on both technology tests. Compassionate, socially oriented students are less likely to find comfort in machines (Al-Dujaily, Kim, \& Ryu, 2013). With no feedback or body language, the clues that help Caring Blues navigate their preferred domain, i.e. people, are missing. The comment below from a student with the Blue temperament was typical of the open-ended responses.

At home I generally steer towards social networking sites. At school I tend to take advantage of listening to music from a flash drive that I supply to help myself focus on work.

These attitudes support and are consistent with the Computational Thinking disposition - ability to communicate and work with others to achieve a common goal or solution. The Blue measure had the highest correlation between temperament and a preference for using computers for web design. Since websites require immense attention to usability, Caring Blue students who are naturally more inclined to consider people throughout the creative process make ideal designers. 


\section{Dutiful Gold - The organizers}

Second to games, work was the most common word in the responses of students with a Gold preference. These students listed more specific computer literacy course activities than any other temperament. This could be due to their tendency to be achievement-oriented and thorough as the highest achieving Gold-oriented student described:

I usually like to make spreadsheets, PowerPoint, and documents for different groups I am in such as Jr. Beta or schoolwork. After that I like to look on Pinterest or Instagram for different ideas to do such as art work, or organizing my room better. [sic]

These attitudes support and are consistent with the Computational Thinking disposition - identifying, analyzing, and implementing possible solutions with the goal of achieving the most efficient and effective combination of steps and resources. This inclination gives the Gold students an advantage over all middle school students because they are more inclined to complete all assigned tasks. Such persistence is likely why the gold measure was a secondary indicator of success on the tests (Table 6 and Table 7).

\section{Multimedia Orange - The presenters}

Students with the Orange temperament listed a large variety of simple to complex computer projects and mentioned more multimedia and visual design applications than any other type. Programs like PowerPoint, Prezi, and Movie Maker match this action-oriented temperament. The combination of elements such as text, video, music, images, and interaction employ several modalities. Games, media, and fun appeal to these students who, like their peers, take their real world preferences with them when they go online. The following summary represents the typical Orange student's response:

Facebook, prezi, microsoft word, skype, pinterest etc. Prezi and Microsoft Word make doing schoolwork easier and more fun. Facebook, skype, and pinterest are great social media websites. [sic]

These attitudes support and are consistent with the Computational Thinking disposition - ability to deal with open-ended problems. The Orange preference is correlated with novelty seeking (Lowry, 1992). This innate aversion to redundancy makes these students responsive to new possibilities.

\section{Guru Green - The analyzers}

The self-proclaimed 'Gamer Geeks', who stated that they used computers often and primarily for fun, were determined, liked to question and gather facts, were the students who demonstrated the greatest tenacity for mastering technology. Green students reported the highest level of computer use with gaming topping the list of favorite pastimes. They mentioned more unique and intricate activities such as programming and networking, along with complex multiuser role-playing games by name. High tech vernacular is evident in middle school as one Green student illustrated:

Terraria, A popular Indie game for PC, Because it is a very interesting game, creating mods for said game, and programming in general. I also enjoy playing with friends. (The few that I have). [sic]

Learning and challenge were underlying themes for several of the Green students.

Web design: fun and challenging activity. Networking and communication: Fun and provides challenges to understand. [sic] 
I like playing games because it gives you time to goof off and relax. I love to watch educational videos on how to have productive bushcraft and survival skills. I love to learn about cool facts on the internet because its cool to know some different things. [sic]

These attitudes support and are consistent with the Computational Thinking dispositions - confidence in dealing with complexity, persistence in working with difficult problems, and tolerance for ambiguity. Green students were not only proficient as measured by the two technology tests, but they displayed the predilection of the computer scientist (ISTE \& CSTA, 2011).

\section{Impact of Course Models on Technology Performance}

The study evaluated the two computer courses in the middle schools, Computer Literacy and Explorations Technology. Computer Literacy had the greatest impact on the performance of the Orange, Gold and Blue students. There was a statistically significant difference in the achievement when compared to Explorations Technology, both courses, or no courses. However, the highest averages for the Green group came from students who participated in Explorations Technology only. The course uses hands-on modules where students can choose their activities, work individually, in pairs or in small groups depending on the projects they select. This format is consistent with research on computer programming class models (Chen, 2010; Hogan, 2009). Students were given opportunities to work actively and then reflect throughout their progression. The push-pull process is conducive to learning coding (Devito Da Cunha \& Greathead, 2004). Affording students the opportunity to actively work, providing immediate feedback, and then reflect, fosters the best environment to refine their computer skills. Explorations Technology is a predominately active/reflective based course.

\section{Methodological and Practical Implications}

Although it is commonly believed that all students love technology, the results indicate that preference and performance differences can be detected as early as $8^{\text {th }}$ grade. The findings also suggest that temperament can be used to differentiate instruction through activity selection, instructional delivery, and cooperative grouping. While games and fun were universal terms for all four temperaments, learning, working, and solving problems were also mentioned as part of the students' computing experience. Adapting lesson plans to incorporate type-based interests and learning styles is a place to start (Sefcik, Prerost, \& Arbet, 2009).

\section{Lesson Planning}

Classroom management poses the greatest challenge to differentiation (Hudson, 2012). In a datadriven, high-stakes test environment, teachers are less inclined to experiment with new methods for fear of missing course objectives (Joseph, Thomas, Simonette, \& Ramsook, 2013). Many school systems use student test results as part of their teachers' evaluations, which serves as a counterincentive to deviate from the norm. If teachers are reasonably successful with their current practices, change is risky. Grading hands-on activities and open-ended assessments with rubrics is time consuming compared to multiple-choice tests. A simple instructional model that targets tech skills and incorporates personal interests would make planning efficient. Students could take technology skills and interest self-assessments, set instructional goals and chart their progress over time (Alaoutinen, 2012). Teachers could simultaneously maintain class summary data and map class activities. Skills could be evaluated on a Likert scale from one to four and reported with appealing metaphorical names like digital Apprentice, Journeyman, Craftsman and Master. Since metaphors make concepts easier to understand and can minimize the negative connotation of numerical values (Ohler, 1999), such trade terms would be appropriate in the technology classroom. 
- Apprentice: possesses little or no experience within a given technology domain.

- Journeyman: has a working knowledge of the basic fundamentals of a technology domain.

- Craftsman: highly skilled in most areas of a technology domain; can apply knowledge to other domains.

- Master: highly skilled, and can apply what he or she knows to helping others; also understands the theory behind a given technology domain.

\section{Complementary Cooperative Pairs}

Pair students on the opposite ends of the technology spectrum to help them strengthen their weaker areas (Cheng, Huang, \& Huang, 2013). The greatest statistical differences occurred between the Blue and Green temperaments. While Green students are more likely to possess strong technology proficiency, they are also more inclined to lack the diplomacy of Blue students. For example, in a web design class, this match could allow 'Blues' to hone technical skills while Greens learn the impact of technology on the user in a website design lesson. Blue students will empathize with the frustration of end users. Green students will likely be able to adapt to the cycle of adjustments often necessary to meet tech specifications on any given project.

Gold and Orange students have complementary attitudes towards completing assignments. Gold students are more task-oriented; Orange students are not as routinized, preferring to explore all possibilities before drawing conclusions. Such a pairing can give students a chance to explore technology creatively while bringing projects to completion. Gold students seek closure which can make them inclined to make quick decisions in the interest of getting a job done. This is helpful for tying together the loose ends of an assignment. However, it is the open-ended preference of the Orange student that often generates the most innovative ideas. Gold gets it done, while Orange makes the journey fun, and 'fun' is key to mastering computers. When possible, include a Communicator, an Analyzer, an Organizer and a Presenter to provide balance. When exploring advanced activities such as coding that require an active/reflective approach to mastering the goals, pair risk-avoidant students (Communicator and Organizers) with risk-taking (Analyzers and Presenters). This can help the former build a tolerance for ambiguous activities, and keep the latter on task (Capretz \& Ahmed, 2010).

\section{Analogous Skill Clusters}

For skills-based lessons, place students in clusters that include individuals whose tech ability levels are close enough to support each other without frustrating some or leaving others behind (Grow, 1991; Meyer, 2011). For example, Apprentices with little proficiency in an area should not be paired with highly proficient Masters without a presence of a Journeyman or Craftsman in the group. Table 15 identifies the matches and mismatches that occur when pairing students with differing degrees of skill.

Table 15: Cooperative Grouping by Tech Skill Level

\begin{tabular}{|l|l|l|l|l|}
\hline & Apprentice & Journeyman & Craftsman & Master \\
\hline Apprentice & Match & Near Match & Mismatch & Severe Mismatch \\
\hline Journeyman & Near Match & Match & Near Match & Mismatch \\
\hline Craftsman & Mismatch & Near Match & Match & Near Match \\
\hline Master & Severe Mismatch & Mismatch & Near Match & Match \\
\hline
\end{tabular}

Adapted from Gerald Grow's (1991) Teaching Learners to be self-directed model 
For projects that combine more than one technology domain, group students heterogeneously by type whenever possible so that each student can fulfill a purposeful role in their assignment

(Singhanayok \& Hooper, 1996). Many times, high-achieving students feel obligated to carry the workload while students with lesser skill sets may feel as if their input does not matter. Successful cooperative groups foster positive interdependence and incorporate individual accountability. Identifying core skills and assigning appropriate project roles will offer all students the chance for success (Randall, 1999).

\section{Limitations and Recommendations for Future Research}

\section{Study Limitations}

The initial proposal was designed for parametric measures, which assume normality of the dependent variable for each of the independent variables. A Shapiro-Wilk analysis of the distribution of the scores by temperament showed that the skewness and kurtosis scores for both Green and Orange were not within normal limits (Table 2 and Table 3 ).

Approximately $61 \%$ of the initial population had a dominant temperament, leaving $39 \%$ with blends of two colors. Future studies should explore a similar design with a population large enough to incorporate blends. There are six two-color blend matches that would bring the total number of possible types to ten.

The technology literacy tests were not good measures of the Explorations Technology course. Explorations Technology is a hands-on science and math-centered program that expands skill beyond the ISTE standards. Modules are selected based on teacher and student interest. Topics include rockets, bridge design, oceanography, plastics and polymers, plumbing, electronic systems, radio repair, and computer hardware repair. Only a few of the course objectives were aligned with the assessments. While the results for the Explorations Technology course were not significant, students who participated in the course had higher scores than those participating in no course at all.

Course grades were not included in this study and would have offered more data on classroom performance by temperament as well as probed the relationship between other courses and technology success. Utilizing other standardized test scores such as the eighth grade Physical Science End of Course Test (EOCT) may have provided a better analysis of course impact on test success.

\section{Recommendations for Future Research}

The raw study data included information on age, gender, socioeconomic status, military affiliation, ethnicity, giftedness, and special education identifiers. There were significant weak to moderate correlations between the independent variables and military family affiliation, giftedness, and socioeconomic disadvantage. These variables were not included in the initial research proposal; however, they do add to the overall potential for instruction.

A gender study would provide insight on females interested in science, technology, engineering and math (STEM) careers. Research could examine the dispositions and attitudes that help females survive and thrive in the technological workforce. Results could aid with recruitment and retention of women in technology fields.

In a study of 356 small businesses in Germany, Meyer (2011) found a negative correlation between age and technology use. The study also showed that in many of the organizations there was a positive relationship between homogenous workgroups and technology adoption regardless of age. Extending this study over the students' remaining high school career would help examine the question as to whether or not technology use changes over time. 
The military installation in the sample community has a major training facility, many high tech jobs and several local contractors. Research in another area of the state could explore the impact of the military population on technology skills. A similar study incorporating samples from other military communities could show the patterns of type based on military affiliation.

The purpose of exploring the technology domains was to examine student performance within the technology standards. Future researchers could investigate test results across the curriculum. Research on syntax by personality type would be helpful in other disciplines. The text analyses in this study suggest that students have identifiable written communication styles. Schwartz et al. (2013) found correlations between social network use, age, gender, and the factors in the BIG Five Factor personality elements: openness, agreeableness, neuroticism, extraversion, and conscientiousness. Exploring possible connections through a study could help teachers evaluate student writing and provide effective feedback

Computer games offer students the opportunity to develop a range of computer skills from keyboarding to problem solving. However, without exposure to the more complex and potentially marketable higher-level skills, students may only remain fluent with basic operations. A pretestposttest study on project-based learning incorporating temperament-based teams could help measure the impact of students as teachers of technology. Game development, evaluation and simulations would be key elements of such a study.

\section{Conclusion}

Previous research has shown there is a relationship between personality type and career choice in the computing industry; however, the data focused primarily on adults in business, industry and post-secondary education. This study explored existing theory with 194 middle school students to ascertain if similar correlations were observable at an earlier age. The results validate previous theses and extend them by pinpointing additional ways in which each temperament approaches technology.

Temperament offers insight on how students learn and process information. Analytical students performed statistically higher on both technology tests and three of the technology domains. This study showed that students who know facts, like to question, and are determined, scored highest on the test. These characteristics are innate to the analytical student but can be fostered in the classroom.

It is important to emphasize that personality type is a powerful tool for predicting trends, not behavior. Type measurements can also change over time (Murphy, 2013). If we can incorporate all students' interests early in their educational journey, educators can provide appropriate support and opportunities in various STEM related fields.

\section{References}

Al-Dujaily, A., Kim, J., \& Ryu, H. (2013). Am I extravert or introvert? Considering the personality effect toward e-learning system. Educational Technology \& Society, 16(3).

Alaoutinen, S. (2012). Evaluating the effect of learning style and student background on self-assessment accuracy. Computer Science Education, 22(2), 175-198.

Barr, D., Harrison, J., \& Conery, L. (2011). Computational thinking: A digital age skill for everyone. ISTE Learning and Leading, 38(6), 20-23.

Bolhari, H., \& Dasmah, T. (2013). Personality preferences: Are learners and teachers at loggerheads? Procedia-Social and Behavioral Sciences, 70, 1636-1640.

Campbell, D. T., \& Stanley, J. C. (1963, 1966). Experimental and quasi-experimental designs for research. Chicago, IL: Rand McNally. 
Capretz, L., \& Ahmed, F. (2010). Making sense of software development and personality types. IT Professional, 12(1), 6-13.

CAPT. (2013). Estimated frequencies of the types in the United States' population. Gainesville, FL: Centre for Applications of Psychological Type.

Chen, L. (2010). Web-based learning programs: Use by learners with various cognitive styles. Computers and Education, 54, 1028-1035.

Cheng, C., Huang, P., \& Huang, K. (2013). Cooperative learning in Lego robotics projects: Exploring the impacts of group formation on interaction and achievement. Journal of Networks, 8, 1529-1535.

Conti, G., \& McNeil, R. (2011). Learning strategy preference and personality type: Are they related? Journal of Adult Education, 40(2), 1-8.

D’Souza, G., \& Colarelli, S. (2010). Team member selection decisions for virtual versus face-to-face teams. Computers in Human Behavior, 26(4), 630-635.

de Vreede, T., de Vreede, G., Ashley, G., \& Reiter-Palmon, R. (2012, January). Exploring the effects of personality on collaboration technology transition. Hawaiian International Conferences on System Science (HICSS), 2012 45th Hawaii International Conference (pp. 869-878), Maui, HI.

Devito Da Cunha, A., \& Greathead, D. (2004). Code review and personality: Is performance linked to MBTI type? Report No.CS-TR-837. School of Computing Science, University of Newcastle upon Tyne.

Eisner, S. (2010). E-employment? College grad career building in a changing and electronic age. American Journal of Business Education, 3(7), 25.

Grow, G. (1991). Teaching learners to be self-directed. Adult Education Quarterly, 41(3), 125-149.

Hogan, R. (2009). Assessment of technology graduate students' learning preference styles utilizing the Myers-Briggs Type Indicator. Journal of Industrial Technology, 25(1), 1-7.

Hudson, P. (2012). How can schools support beginning teachers? A call for timely induction and mentoring for effective teaching. Australian Journal of Teacher Education, 37(7), 70-84.

International Society for Technology in Education (ISTE) \& Computer Science Teachers Association (CSTA) (2011). Computational thinking in K-12 education leadership toolkit. Retrieved from http://csta.acm.org/Curriculum/sub/CurrFiles/471.11CTLeadershiptToolkit-SP-vF.pdf

ISTE. (2007). National educational technology standards (NETS) for students. Retrieved from http://www.iste.org/standards/ISTE-standards/standards-for-students

Joseph, S., Thomas, M., Simonette, G., \& Ramsook, L. (2013). The impact of differentiated instruction in a teacher education setting: Successes and challenges. International Journal of Higher Education, 2(3).

Khan, S. A., Javaid, M. A., \& Farooq, U. (2015). Evaluation of the effectiveness of cooperative learning method versus traditional learning method on the writing ability of the students. Asian Journal of Management Sciences \& Education, 4, 1.

Lowry, D. (1992). Keys to personal success. Corona, CA: True Colors International.

Luse, A, McElroy, J., Townsend, A., DeMarie, S. (2013) Personality and cognitive style as predictors of preference for working in virtual teams. Computers in Human Behavior 29, 1825-1832.

McPeek, R., Urquhart, C., Breiner, J., Holland, D., \& Cavalleri, D. (2011). The impact on student academic performance and attitudes of psychological type and its introduction to the classroom. Journal of Psychological Type, 71(3).

Meyer, J. (2011). Workforce age and technology adoption in small and medium-sized service firms. Small Business Economics, 37(3), 305-324.

Murphy, E. (2013). Some pros, cons, and cautions about researching type in schools. Journal of Psychological Type, 73(1), 1-6. 
Nickels, D., Parris, J., Gossett, C., \& Alexander, P. (2010). Developing collaboration skills: A mixed temperament approach to teamwork. Business Studies Journal, 2(2), 101-116.

Ohler, J. (1999). Taming the beast: Choice \& control in the electronic jungle. Bloomington, IN: Technos Press.

Ohler, J. (2010). Digital community, digital citizen. Thousand Oaks, CA: Corwin Press.

Pink, D. (2006). A whole new mind: Why right-brainers will rule the future. New York: Riverhead Books.

Pink, D. (2009). Drive: The surprising truth about what motivates us. New York, NY: Riverhead Books.

Purcell, K., Heaps, A., Buchanan, J., \& Friedrich, L. (2013). How teachers are using technology at home and in their classrooms. Washington, DC: Pew Research Center's Internet \& American Life Project. Retrieved from http://www.pewinternet.org/2013/02/28/how-teachers-are-using-technology-at-homeand-in-their-classrooms/

Randall, V. (1999). Cooperative learning: Abused and overused? The Education Digest 2(65), 29-32.

Sadeghi, N., Kasim, Z., Tan, B., \& Abdullah, F. (2012). Learning styles, personality types and reading comprehension performance. English Language Teaching, 5(4), 116.

Schwartz, H., Eichstaedt, J., Kern, M., Dziurzynski, L., Ramones, S., Agrawal, M., ... Ungar, L. (2013). Personality, gender, and age in the language of social media: The open-vocabulary approach. PLoS ONE, 8(9), e 73791. doi:10.1371/journal.pone.0073791

Sefcik, D., Prerost, F., \& Arbet, S. (2009). Personality types and performance on aptitude and achievement tests: Implications for osteopathic medical education. The Journal of the American Osteopathic Association, 109(6), 296-301.

Singhanayok, C., \& Hooper, S. (1996). The effect of cooperative learning and learner control on students' achievement, option selections, attitudes, education technology, Research and Development, 46(2), 17 25 .

Thorne, A., Korobov, N., \& Morgan, E. (2007). Channeling identity: A study of storytelling in conversations between introverted and extraverted friends. Journal of Research in Personality, 41(5), 10081031 .

Uffen, J., Kaemmerer, N., \& Breitner, M. (2013). Personality traits and cognitive determinants: An empirical investigation of the use of smartphone security measures. Journal of Information Security, 4(4).

Wichard, J. (2006). Reliability and validity of True Colors. Retrieved from http://www.truecoloursglobal.com/images/PDF/Reliability_Validity_study.pdf

\section{Biography}

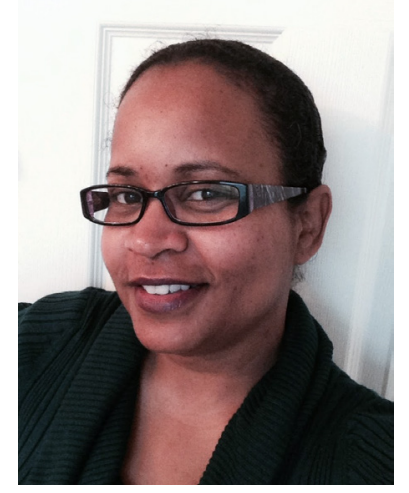

Sabrina Sterling, EdD is a Technology Instructional Specialist in a K12 School System whose main focus is administering the student longitudinal data and test-generating program. She also teaches computer applications working primarily with productivity and multimedia programs including Google Apps for Education, presentation creation, photo editing, video production, and any other high-energy program thrown her way. She has worked as an elementary computer lab instructor, a regular education teacher as well an online adjunct for a state university. Sabrina has presented at the Georgia Educational Technology Conference, the International Society for Technology in Education (ISTE) conference as well as the Oklahoma Early Childhood and Mid-Del Early Childhood conferences. She has written articles for Ed Tech Magazine, Techlearning.com, Distance Learning and School Library Journal. Sabrina holds a Bachelor of Science degree in Early Childhood Education, Masters and Specialist degrees in Instructional Technology, and a Doctorate in Teaching and Learning. 